\title{
Chapter 13 \\ Relevance of Individual-Level Residential \\ Outcomes for Segregation Theory
}

The residential outcomes that give rise to segregation index scores can be assessed in terms of whether they are relevant for investigating different theories of segregation dynamics. In the final analysis, theories of segregation must reckon with the micro-level dynamics that produce the residential patterns that aggregate indices summarize. It is easy to see how the residential outcome registered by $\mathrm{S}$ - namely, area racial mix $(\mathrm{p})$ - is relevant for theories of residential attainment dynamics. For example, Lieberson advanced the hypothesis that segregation arises in part when Whites strive to maintain high levels of same-group contact and avoid more than incidental levels of contact with minorities (Lieberson 1980, 1981: 75; Lieberson and Carter 1982). Combining this hypothesis with the assumption that Whites have greater ability to influence residential dynamics leads to straightforward predictions regarding how $\mathrm{S}$ will vary when city racial composition varies over time or across cities. For example, the hypothesis that discrimination by Whites serves to keep White contact with Whites from falling below fairly high levels (say $85 \%$ or higher) leads to the prediction that $\mathrm{S}$ will vary as a positive, nonlinear function of proportion Black in the city. ${ }^{1}$

The implications for $\mathrm{D}, \mathrm{G}, \mathrm{R}$, and $\mathrm{H}$ are much more complicated and indirect. I not aware of any theories that suggest Whites may specifically strive to attain or avoid particular levels on the residential outcomes that determine the values of these indices. Figure 5.1 introduced earlier shows D, G, R, and $\mathrm{H}$ score values of p differently across cities depending on the racial mix of the city. For present discussion, consider D when formulated as a difference of means when neighborhoods are

\footnotetext{
${ }^{1}$ In a city where proportion Black is very low - say $1-5 \%, \mathrm{~S}$ can be low since Blacks can experience high levels of contact with Whites without causing problems for White's desires to have limited contact with Blacks and high contact with Whites. This changes when proportion Black increases. In order to maintain White contact with Whites $\left(\mathrm{P}_{\mathrm{WW}}\right)$ at 0.90 or higher as proportion Black in the city increases, Black contact with Whites $\left(\mathrm{P}_{\mathrm{BW}}\right)$ must fall. This will cause $\mathrm{S}$ to increase since, in the two-group case, $\mathrm{S}=\mathrm{P}_{\mathrm{WW}}-\mathrm{P}_{\mathrm{BW}}$. The relationship will be nonlinear. Initially, $\mathrm{S}$ will increase rapidly as proportion Black in the city $(\mathrm{Q})$ increases; then the rate of increase will decline.
} 
scored as either 0 or 1 depending on whether $\mathrm{p}$ for the area exceeds $\mathrm{P}$ for city. In this formulation, a neighborhood where $\mathrm{p}$ is 90 would be scored 1 in a lower-P city such as Birmingham and 0 in a higher-P city such as Minneapolis. The literature on race and residential dynamics gives no basis for expecting residential outcomes to revolve around these $0-1$ scores instead of the original values of $p$. In contrast, the literature does provide a basis for expecting $\mathrm{p}$ scored in its natural metric to predict residential dynamics; specifically, Lieberson hypothesizes that Whites in all cities will prefer residential outcomes of $\mathrm{p}=95$ over $\mathrm{p}=85$ and $\mathrm{p}=85$ over $\mathrm{p}=75$, and so on. Thus, one can plausibly argue that $\mathrm{S}$ registers White-Black differences on residential outcomes that are meaningful in residential attainment dynamics. I know of no basis for making this kind of argument for the residential outcomes registered by $\mathrm{D}, \mathrm{G}, \mathrm{R}$, or $\mathrm{H}$.

With this in mind, it is interesting to note that the results presented earlier in Table 10.1 indicate that the impact of relative minority size on segregation is much greater in the analysis of $\mathrm{S}$ than in the analyses for $\mathrm{D}$. For example, cities that are at $4 \%$ and $25 \%$ Black are predicted to differ by 24.0 points on $\mathrm{S}$ but only 1.6 points on D. ${ }^{2}$ Furthermore, the effects of relative minority size on patterns of residential contact relating to $\mathrm{S}$ are more sensible in my view. For $\mathrm{S}$, both White and Black contact with Whites declines as relative minority size increases, but the rate of decline is greater for Blacks thus leading to higher levels of group separation as minority size increases. This pattern is consistent with the Lieberson hypothesis. Contact with Whites as registered by $\mathrm{D}$ increases for both Whites and Blacks as relative minority size increases. These effects do not lend themselves to ready substantive interpretation and in any event the pattern has minimal implications for city-level variation in segregation across cities.

I conclude this discussion by noting again that it is unproductive to claim that any one segregation index is best for all circumstances and purposes. Accordingly, I advocate the following position. Ideally, researchers should be able to offer a sound justification for why a particular index is an appropriate choice for the substantive question(s) they are investigating. My comments endorsing $\mathrm{S}$ are rooted in a particular set of research interests. I am interested in segregation as it relates to racial stratification and socioeconomic inequality and thus I assign priority to the implications segregation may have for group differences in life chances linked with residential outcomes. From this vantage point, I believe S registers outcomes that are meaningful to individuals and households and relevant to residential attainment dynamics that produce aggregate segregation. But I do not argue that this is the only valid vantage point from which to advocate the use of a particular segregation index. Others may offer good justifications for viewing other indices as valid and attractive either for addressing specific research questions that interest them or on various practical grounds. For example, while I have expressed reservations about $\mathrm{G}$ and $\mathrm{D}$ based on the unusual way they register group differences in area racial mix, I expect many researchers will continue to use them, especially D, in order to main-

\footnotetext{
${ }^{2}$ These values on relative minority size translate to 0.14 and 0.50 on the square root of minority proportion. The difference of 0.34 is multiplied by the effect coefficients of 4.79 and 70.51 in the equations for $\mathrm{D}$ and $\mathrm{S}$, respectively. This translates into $1.63=0.34(4.79)$ and $23.97=0.34(70.51)$.
} 
tain continuity with previous research and because they find D's aggregate-level "volume of movement" interpretation to be attractive.

I conclude with a practical observation. It is that sometimes index choice is not that important and it is easy enough to check to determine whether this is the case. Recall that the analyses reviewed in Chap. 6 provided evidence that popular indices of uneven distribution correlated at very high levels $\left(r^{2} \geq 0.85\right)$ when group size was not highly imbalanced (e.g., when $0.10 \leq \mathrm{P} \leq 0.90$ ). It is easy to see if this welcome situation prevails; examine the correlation of scores for D and S and check to see if results differ using these two indices. When these two measures correlate closely, all popular measures correlate closely. Accordingly, if the correlation is high and the key findings do not differ by index, it is safe to conclude that index choice is not an important factor in this situation.

When $\mathrm{D}$ and $\mathrm{S}$ are not highly correlated one must give the issue of index choice more attention. To the extent possible one should provide a sound justification for choosing to use a particular index. Additionally, it would be wise to check for and acknowledge whether key empirical findings and substantive conclusions vary depending on index choice.

\section{References}

Lieberson, S. (1980). A piece of the pie: Blacks and White immigrants since 1880. Berkeley: University of California Press.

Lieberson, S. (1981). An asymmetric approach to segregation. In C. Peach, V. Robinson, \& S. Smith (Eds.), Ethnic segregation in cities (pp. 61-82). London: Croom Helm.

Lieberson, S., \& Carter, D. K. (1982). A model for inferring the voluntary and involuntary causes of residential segregation. Demography, 19, 511-526.

Open Access This chapter is licensed under the terms of the Creative Commons AttributionNonCommercial 2.5 International License (http://creativecommons.org/licenses/by-nc/2.5/), which permits any noncommercial use, sharing, adaptation, distribution and reproduction in any medium or format, as long as you give appropriate credit to the original author(s) and the source, provide a link to the Creative Commons license and indicate if changes were made.

The images or other third party material in this chapter are included in the chapter's Creative Commons license, unless indicated otherwise in a credit line to the material. If material is not included in the chapter's Creative Commons license and your intended use is not permitted by statutory regulation or exceeds the permitted use, you will need to obtain permission directly from the copyright holder.

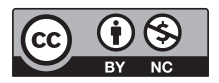

